\title{
Investigation of Call Drop in a Cognitive GSM Network
}

\author{
Adigwe Wilfred \\ Member, \\ Nigeria Computer Society (NCS), \\ Member, Computer Professionals \\ Registration Council of Nigeria (CPN) \\ Department of Computer ScienceDelta State \\ Polytechnic Ozoro, Delta State Nigeria
}

\author{
Alumona Theophilus \\ Department of Electronic and \\ Computer Engineering \\ Nnamdi Azikiwe University \\ , Awka, Nigeria
}

\begin{abstract}
Investigation of call drop is categorized as network monitoring and evaluation, whose focus is to evaluate the performance of the quality of service (QOS) of a radio network in terms of call drop rate. The data used for this work was retrieved from a recording and monitoring customized software called FACTS integrated in the MTN network life node Base station controller (BSC) located along BeninAsaba Expressway with over 70 Base station transceivers (BTSs) connected to it. The data was measured on a daily, weekly and Monthly interval for clear understanding of the analysis. This network experienced its highest call drop rate between $3 \mathrm{pm}$ and $4 \mathrm{pm}$ with about $44 \%$ calls dropped in a day, $25.2 \%$ calls dropped on Monday within a week and $24.156 \%$ calls dropped in December in a six Months period. This excessive call drop was a result of insufficient BTSs, unavailability of Spares to replace defective ones, longer response time for handoff request and improper matching of BTSs and even Master switching centre (MSC) leading to poor or delay handshaking among BTSs and BSCs.
\end{abstract}

\section{Keywords}

Call performance index, Call drop rate, Node, Handover success rate and FACTS.

\section{INTRODUCTION}

Call drop is one of the greatest challenges of GSM operators because it degrades the quality of the service provided to mobile subscribers especially as the numbers of subscriber increases. This will definitely affect their profit margin [1]

The obstacle in the development of the cellular network involved the problem created when a mobile subscriber moves from one cell to another during a call. The adjacent areas do not use the same radio channels, a call must either be dropped or transferred from one radio channel to another when a user crosses the line between adjacent cells. Because dropping the call is unacceptable, the process of handoff was created. Handoff occurs when the mobile telephone network automatically switch an active call from one cell to another, the switching of current communication channel could be terms of time slot, frequency band or code word to a new base station [2-5]

Call drop is one of the most important quality of service indexes for monitoring performance of a cellular networks. For this reason, the objective of this paper is to investigate the number of call drops in a given GSM network, analyze it and recommend possible ways of minimizing it within the network so as to help the operator's network planning team to plan upgrading when necessary. When call traffic data are collated and analyzed properly it will also help them to predict and carry out necessary network optimization which will result to improve quality of service that is the ultimate desire of every mobile subscriber.

Since there is a regulatory commission that regulate call performance index and has the minimum acceptable benchmark for the quality of service render to mobile subscribers even as the users increases, it becomes imperative to investigate the signal traffic in a given network in terms of call drop rate. This work collated call traffic data from a life node along Asaba - Benin expressway with the aid of customized software called FACTS integrated into the entire network for monitoring and controlling equipment within the network.

The analysis in this paper is to see how to help operators improve on the quality of service given to their subscribers with better services. This will possible since the analysis done in the work will give a better knowledge of expected bearer call traffic in their network and then make arrangement for network resources suitable for such traffic.

The rest of this paper is organized as follows; section 2 discussed prior related work. Section 3 described the methodology for retrieving traffic data within a node. Section 4 , this is where the implementation of this work is analyze and also share how the call traffic was gather from the experimental test bed of investigation. Then section 5, present, analyze and simulate the data obtained with the aid of MATLAB software. Finally section 6 , concluded the work, recommendation to further reduce call drop in a GSM network was presented.

\section{RELATED WORKS}

There are several papers which study call performance in cellular networks and, in particular, how the drop call is related to traffic parameters.

D. Hong and S. Rappaport [6] is a milestone in performance analysis of mobile radio systems. Drop call probability is analyzed with the classical assumption of exponential distribution for the call holding time. In particular, it puts emphasis on handover and its effects on performance. Handover is considered the main cause for call dropping.

The other classic work by P. V. Orlik and S. S. Rappaport [7] shows how drop call and blocking probabilities are affected by user mobility, considering different patterns for movements of mobile equipments. Again, handover is considered the cause of call dropping.

M. Rajaratnam and F. Takawira [8,9] analyzed in depth the influence of handover on mobile network performance]. They considered different patterns for user mobility. Also, the relationship between handover failure and call dropping was analyzed. 
In X. Chao and W. Li work [10], handover and call dropping are studied considering a cellular mobile communication network with multiple cells and different classes of calls, that is, multiple types of service are assumed. Each class has different call-holding and cell-residence times.

N. Nasser [11] estimates the drop-call probability considering a multimedia wireless network. An adaptive bandwidth allocation algorithm is exploited to improve system performance and to reduce, in particular, handover-blocking probability.

Whereas the previous cited papers assume wireless networks with an infinite number of users, G. Boggia, P. Camarda, and N. Di Fonzo [12] describes what happens when a finite user population is taken into account. In particular, the study considers also the presence of a hierarchical cellular structure.

The common denominator of all the previous works is assumptions about network characteristics. They implicitly consider that an appropriate radio planning has been carried out; therefore, propagation conditions are neglected. Moreover, they do not deal with mobile equipment failure and network equipment outages. Such assumptions implied that calls are dropped only due to the failure of the handover procedure. That is, the connection of an active user changing cell several times is terminated only due to the lack of communication resources in the new cell. For this reason, this research focused on traffic data retrieved from an accurate source i.e FACTS to investigate the number of call drops in this Network and suggest possible solution to reduce it.

\section{METHODOLOGY}

In a GSM systems the criteria for requesting hard handover may be based in one or more of these parameters such as estimates of the received signal power, bit error rate (BER) and block error/ erasure rate (BLER), received quality of speech (RxQual), distance between the phone and the BTS (estimated from the radio signal propagation delay) e.t.c.

There are various techniques used for measuring cell drop, these are:

1. Protocol Analyzer

2. Direct test

3. Operation and monitoring Center software(OMCS)

4. Spatial Network monitoring Tool (GIS)

\subsection{Protocol Analyzer}

The protocol analyzer application is a multi-protocol application that allows Engineer to simultaneously record and analyzed fibers channel, serials ATA and SAs traffic. Engineers can attach two or more different types of analyzer into a multiprotocol test and then configure the analyzer to record simultaneously. A serial ATA is connected to a bridge, and the bridge, in turn is connected to fiber channel HTB, two cascaded analyzer are placed on the links and administered by a laptop running MPA. In this setup, MPA will be able to instruct both analyzer to simultaneously record, give the recordings a common timestamp, and afterwards analyze the two traces side by side

\subsection{Drive Test}

A drive on predefined routes covered by the network was carried out and periodically calls were initiated. The results (e.g dropped calls, unsuccessful handoff, low quality audio, signal strength) are transferred from MS to a dedicated PC, where the respective data are available for post processing.

\subsection{Operational and Monitoring Center System (OMCS)}

With this measurement tool, several counters can be activated in BSS and the NSS from the OMC to provide the central office with the most important data about network quality of various counters for all kinds of events permanently provide the network operator with information about the state and quality of the network. Examples are counters for the number of incoming or outgoing handover, call drops before, during and after assignment or dropped calls due to missing network or radio resources.

The advantages of OMC are as follow:

- It provides the result about quality of the entire network rather than single BTS or BSCs

- It provides feedback about network quality in real time

- It reassures event and provide the result of the respective counters to the operator

\subsection{Spatial Network Monitoring Tool (with GIS)}

It is a measuring and monitoring tools that have in- built intelligence using script to highlight certain rows indifferent colors to draw attention to cells that had violated the network stipulated KPIs [13]. A number of statistical plots like bar charts, histograms, pie charts e.t.c. have been incorporated to give better insight into understanding these parameters. With these charts, it is possible to do a comparative analysis e.g plotting call drop rate against time. The geographical area of the network is very important to optimization/monitoring Engineer. So GIS is integrated into the normal OMC to produce dynamic maps used for monitoring the network's status. GIS is the best technology for marking faster, informed technical decisions especially if such decision are spatial. Using a map in network monitoring can provide a dramatic improvement over traditional

optimization methods, allowing the Engineer to see a precise up-to- date picture of the entire network and quickly identify the trouble spots.

The requirements for the application of GIS to GSM network monitoring are:

(i) Predicted coverage array - this forms the bedrock for producing dynamic maps used for monitoring the network's status. It is a collection of geo-referenced polygons in space that represent the radial distance of the signal strength away from each call based on the signal's interaction with environmental factors like terrain, water, forest, residential area e.t.c it is produce using a specific algorithm in a standard radio frequency planning tool.

(ii) Network parameters or counter - this monitored or captured network status of every single operational cell in the network and store them in a standard database like oracle or SQL server.

This spatial monitoring tool which FACTS is a good Example bends e.g In Nigeria $900 \mathrm{MHz}$ and $1800 \mathrm{MHz}$ different type of dynamic maps based on:

- $\quad$ Traffic carried in Erlang 
- Percent traffic channel congestion

- Percent call drop rate

- Mean hold time

- Percent traffic channel availability

- Percent network resource utilization

- Cell down

- $\quad$ Processor load balancing

- Network dimension

Advantages of spatial monitoring tool

(i) It simplifies the identification and resolution of network and service performance issues, resulting in maximized network performance, lower capital equipment costs and enhanced service

(ii) It accelerate deployment and support of new technologies and service

(iii) It helps to evaluate the impact of voice service on radio network resources to better determine the requirement for future network expansion and the addition of new services

(iv) It reduces operational expenses by minimizing the time and expertise required to perform common network analysis

(v) It create an insightful method of better dimensioning network

\subsection{Significant Parameters to Assess the Performance of GSM Networks}

(i) Service accessibility: The ability of a service to be obtained, within specified tolerance and other given conditions, when requested by the user [14]

Accessibility $=$ Total No of successful calls setup

Total calls Accesses to Network

(ii) Call completion Rate: Is the ratio of the number of completion call attempts to the total number of call attempts at a given point of a network

(iii) Answer seizure ratio (ASR): is the ratio of the number of successful calls over the total number of outgoing calls from a carrier's network during a specified time interval.

(iv) Call setup success rate: the number of the unblocked call attempts divided by the total number of call attempt

Call setup success rate $=(1-$ blocking probability $) \times 100 \%$ ....... (2)

(v) Call drop rate : Is the number of dropped calls divided by the total number of call attempts

Call drop rate $=(1-$ call completion ratio $) \times 100 \%$

(vi) Handover success rate : Is the ratio of the number of successfully completed handover to the total number initiated handovers.

(vii) Busy hour traffic channel congestion (\%): Is the percentage congestion of the TCH measured at the busy hour and is given by:
Busy hour TCH Traffic ( Erlang) - Average TCH traffic (Erlang) Busy Hour TCH Traffic (Erlang)

$\times 100$

(viii) Sector: A call is divided into sector. The antenna used in the most base with station is dual band $(900 \mathrm{MHz}$ and $1800 \mathrm{MHz}$ ). This sector is divided in A, B, C with an angular displacement of 120 each

(ix) Node: Is a base station controllers that coordinate and control the activities of group of BTSs connected to it.

\section{IMPLEMENTATION}

The aim of this paper is to evaluate the performance of a radio network in terms of call drop rate, call setup success rate, handoff success rate, accessibility, traffic carried in Erlang e.t.c in other to determine hour efficient and effective a network can be. The experimental testbed for this work is one of the MTN mega BSC situated along Asaba-Benin expressway in Nigeria. This BSC controls over 70 BTSs connected to it via various sizes of microware dishes through an abis interface. All the data used for this research was generated from MTN OMC report used.

Network management and monitoring call performance software called FACTS which was customized for MTN network (was) used to retrieve the data from this life node.

The research instruments used are as follows:

(i) Laptop

(ii) Intranet connectivity

(iii) Network monitoring and recording software (FACTS)

(iv) Main server

\subsection{Procedure for Data Collection}

This research was carry out at MTN office along Asaba-Benin expressway where they have $16 \mathrm{BSCs}$ and their MSC with one of quality of service to retrieve data used for this work. But only one BSC with ID name ABSC11 was used for this research. This particular BSC has over 70 BTSs connected to it.

The following procedures were adopted for the collection of data for this work:

(i) Connection to intranet - The laptop used for retrieving the data was switch on, setup and connected to the operator's intranet

(ii) Connection to FACTS software - After connecting to the intranet, then click on the intranet explorer and type http://facts.mtnnigeria.net/facts in the URL. This command took us to the login page where username and password was requested for

(iii) Connection to network performance - After the username and password has been provided by the user, the FACTS page opened and then clicked on "network" which was displayed in the left pane of the FACTS page. So from the option displayed after the clicking of "network", "network performance" was selected.

(iv) Retrieval of Data - From the option chosen above, we then key in the details required for this work such as Vendor. Interval under query i.e hourly, weekly, monthly e.t.c. then we 
chose the "BSC" under layer option and "ASBSC11" under element option

All the data for the network performance was displayed and opened with Microsoft excel. It was tabulated, presented and analyzed in the next section

\section{RESULT}

Table 1 shows that call drop in this network is probably due to lack of network system resources or system failure. More so, some of the calls may gain access to the network as attempted calls and yet not reach the target subscribers, just a fraction of the total call arrivals, call drop, handoff with time and their corresponding average values.

Table 1. Statistics for node measured for 24 hours

\begin{tabular}{|c|c|c|c|}
\hline $\begin{array}{c}\text { Time in } \\
\text { hour }\end{array}$ & $\begin{array}{c}\text { Calls } \\
\text { attempted }\end{array}$ & $\begin{array}{c}\text { Calls } \\
\text { answered }\end{array}$ & $\begin{array}{c}\text { Call } \\
\text { drop }\end{array}$ \\
\hline $00.00-01.00$ & 4020 & 3648 & 372 \\
\hline $01.00-02.00$ & 4867 & 4527 & 340 \\
\hline $02.00-03.00$ & 3425 & 3107 & 318 \\
\hline $03.00-04.00$ & 2125 & 1834 & 291 \\
\hline $04.00-05.00$ & 3392 & 1292 & 2100 \\
\hline $05.00-06.00$ & 4403 & 2980 & 1423 \\
\hline $06.00-07.00$ & 11259 & 7849 & 3410 \\
\hline $07.00-08.00$ & 17438 & 9347 & 8091 \\
\hline $08.00-09.00$ & 23679 & 12588 & 11091 \\
\hline $09.00-10.00$ & 29785 & 16674 & 13111 \\
\hline $10.00-11.00$ & 28767 & 15981 & 12786 \\
\hline $11.00-12.00$ & 25649 & 15564 & 10085 \\
\hline $12.00-13.00$ & 24309 & 10881 & 13428 \\
\hline $13.00-14.00$ & 23561 & 14859 & 8702 \\
\hline $14.00-15.00$ & 28675 & 18670 & 10005 \\
\hline $15.00-16.00$ & 36009 & 20073 & 15936 \\
\hline $16.00-17.00$ & 15678 & 9578 & 6100 \\
\hline $17.00-18.00$ & 14324 & 9761 & 4563 \\
\hline $18.00-19.00$ & 13881 & 10525 & 3356 \\
\hline $19.00-20.00$ & 15532 & 10100 & 5432 \\
\hline $20.00-21.00$ & 10894 & 9029 & 1865 \\
\hline $21.00-22.00$ & 13490 & 10069 & 3421 \\
\hline $22.00-23.00$ & 7208 & 6227 & 981 \\
\hline $23.00-24.00$ & 3107 & 2907 & 200 \\
\hline
\end{tabular}

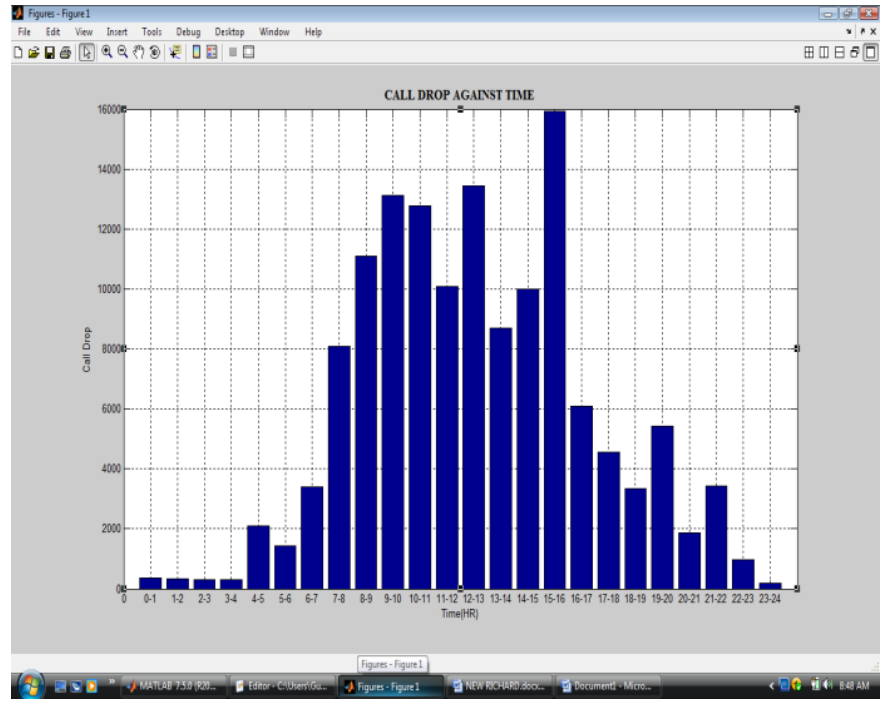

Figure 1: Call drop measured 24 Hours in a day

From Figure 1 between 12am to $4 \mathrm{am}$ the total number of call drop in the network was minimal. This was because the trunks were free as almost all the calls reached the target subscriber. The few calls drop experienced was as a result of handoff.

This probably, because people have gone to bed and only few people are moving out of their base station. Between $3 \mathrm{pm}$ and $4 \mathrm{pm}$ the call drop rose to 15936 out of 36009 calls attempt which represent $44 \%$ of the calls attempted.

Table 2. Statistics for node measured for one week

\begin{tabular}{|l|l|l|l|}
\hline $\begin{array}{l}\text { Time in } \\
\text { Day }\end{array}$ & $\begin{array}{l}\text { Calls } \\
\text { attempted }\end{array}$ & $\begin{array}{l}\text { Calls } \\
\text { answered }\end{array}$ & $\begin{array}{l}\text { Call } \\
\text { drop }\end{array}$ \\
\hline Sunday & 265890 & 243956 & 21934 \\
\hline Monday & 396734 & 296690 & 100044 \\
\hline Tuesday & 375690 & 296789 & 78901 \\
\hline Wednesday & 369956 & 345986 & 23970 \\
\hline Thursday & 358690 & 286674 & 72016 \\
\hline riday & 333268 & 255716 & 87552 \\
\hline Saturday & 316543 & 224848 & 91695 \\
\hline
\end{tabular}

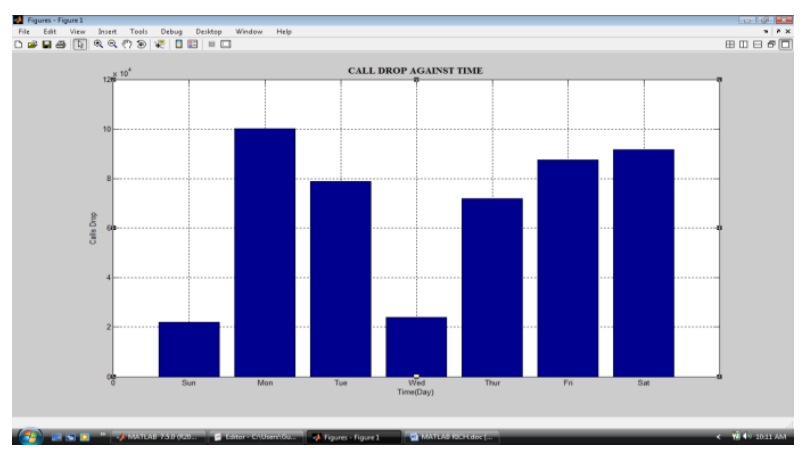

Figure 2: Call drop measured for one week 
In Figure 2, the maximum call drop was experienced on Monday with about 10044 call drops which is about $25.2 \%$ of the total call attempted that day i.e about $74.8 \%$ calls were answered. The call drops was high as a result of the carrier cells been overloaded. This is so, because so many calls arrived at the network and service, GSM uses time slot and each subscriber occupies a time slot at any given time

Table 3. Statistics for node measured for six Months

\begin{tabular}{|l|l|l|l|}
\hline $\begin{array}{l}\text { Time in } \\
\text { Months }\end{array}$ & $\begin{array}{l}\text { Call } \\
\text { attempted }\end{array}$ & $\begin{array}{l}\text { Calls } \\
\text { answered }\end{array}$ & Call drop \\
\hline December & 15804352 & 11853264 & 3951088 \\
\hline January & 10002166 & 7815692 & 2186474 \\
\hline February & 9009657 & 7264901 & 1744756 \\
\hline March & 8802281 & 7198946 & 1603335 \\
\hline April & 12807657 & 10416472 & 2391185 \\
\hline May & 9001114 & 7650947 & 1350167 \\
\hline
\end{tabular}

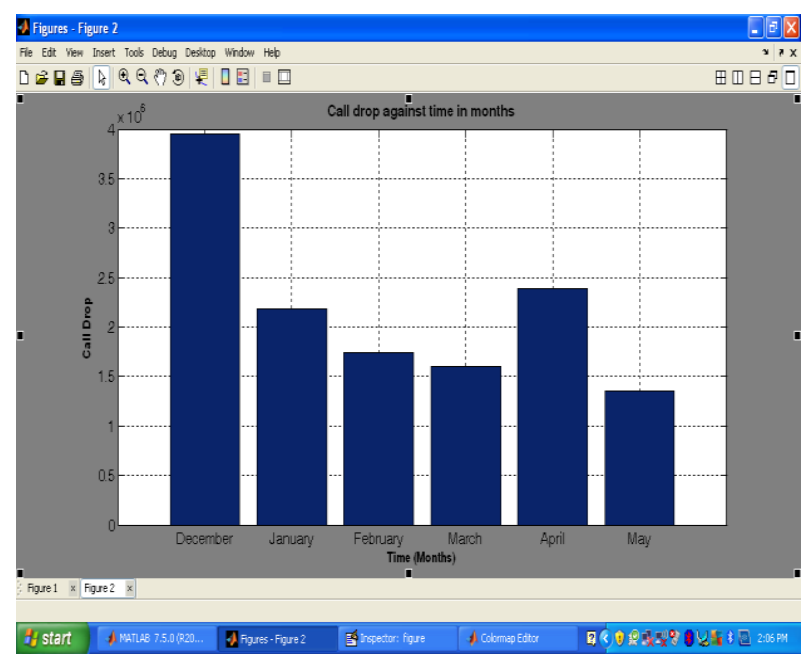

Figure 3: Call drop measured for six months period

From Fig 3, the maximum call drop was experienced in December with about 395188 calls, dropped which represent $25 \%$ of the total calls attempted that month i.e. only about $75 \%$ calls were answered.

The calls drop was high as a result of more subscribers visiting this node for festive celebration, trading, religious activities, various celebration and even to spend their vacation with their love ones which result to network congestion of the node. This might as well be caused as a result of delay in resolving either power or transmission problem within the network because of traffic jam everywhere. The call drop was minimal in May with about $15 \%$ of the calls dropped

\section{CONCLUSION AND RECOMMENDATION}

This paper was able to find out from the traffic data reassured, that excessive call drop in the network was as a result of :

(i) The response time for handoff request was longer (ii) The base stations are not enough for the number of subscriber

(iii) Non availability of enough spares to replace defective radio equipment

(iv) Improper handshake matching between BTSs as well as BSC and MSC

(v) The signaling of the handoff and the MAHO algorithm also impact the call drop rate

\section{RECOMMENDATION}

Considering the findings from this work, the following are ways to reduce the excessive call drop in a GSM network

(i) Operators should constantly carry out proper signaling traffic evaluation to know the capacities of their network equipment so to meet the expected number of subscribers within the network

(ii) Operators should make a proper provision for redundancy for future expansion for prospective subscribers

(iii) There is need to increase their cell size to minimize handover

(iv) As they increase their cell sizes, there is also a need to shorten the handoff request in other to reduce call drop rate

(v) There is need to maintain the specified co- channel and adjacent channel interference level in each cell during busy hour (i.e the worst interference case)

(vi) There is need for optimization in the network in terms of system parameter adjustment as subscribers increases at all time.

(vii) Since power epileptic is a major problem in Nigeria, operators must always have at least three power supply source which one can be PHCN supply while the other two can be generators with regular diesel supply and adequate maintenance. And a high capacity backup battery for DC voltage equipment such as Transmission links i.e Microwave units and Alarm monitoring panel must be provided to support the power supply source.

Above all, to reduce call drop rate effectively and economically, it is important we have more infrastructure collocation companies in Nigeria where by more than three or four network operators can share towers, power supply, cooling system if indoor unit BTS is used and space which will lead to increment in their cell sizes.

\section{REFERENCES}

[1] Kim, Y., Lee, K., and Chin, Y., 1996. Analysis of Multilevel Threshold Handoff Algorithm, Global Telecommunications Conference (GLOBECOM'96), vol. 2, pp. 1141-1145

[2] Tekinay, S., and Jabbari, B., 1991. Handover and Channel Assignment in Mobile Cellular networks, IEEE Communications Magazine, vol.29, (November 1991), pp. 42-46.

[3] Gregory, P. P., 1996. Trends in Handover Design", IEEE Communications Magazine, vol. 34, (March 1996), pp. $82-90$ 
[4] Marichamy, P., Chakrabati, S., and Maskara, S. L., 1999. Overview of handoff schemes in cellular mobile networks and their comparative performance evaluation", IEEE VTC'99, vol. 3, pp. 1486-1490.

[5] Nishint, D. Tripathi, Jeffrey H. Reed and Hugh F. VanLandinoham, 1998. Handoff in Cellular Systems, IEEE Personal Communications, vol.5, December 1998, pp. 26-37.

[6] Hong, D., and Rappaport, S., 1986. Traffic model and performance analysis from cellular mobile radio telephone system with prioritized and nonprioritized handoff procedures," IEEE Transactions on Vehicular Technology, vol. 35, no. 3, pp. 77-92 .

[7] Orlik, P. V., and Rappaport, S. S., 1998. A model for teletraffic performance and channel holding time characterization in wireless cellular communication with general session and dwell time distributions, "IEEE journal on selected Area in communication, vol. 16, no. 5, pp788-803

[8] Rajaratnam, M., and Takawira, F., 2000. "Nonclassical traffic modeling and performance analysis of cellular mobile network with and without channel reservation, "IEEE Transactions on Vehicular Technology, vol. 49, no. 3, pp. $817-834$
[9] Rajaratnam, M and Takawira, F., 2000. Handoff traffic characterization in cellular network under nonclassical arrivals and service time distributions, IEEE Transactions on Vehicular Technology, vol. 50, no. 4, pp. 954-970.

[10] Chao, X and Li, W.,2005. Performance analysis of a cellular network with multiple classes of calls, IEEE Transactions on communications, vol. 53, no. 9, pp 1542-15550.

[11] Nasser, N., 2006. Enhanced blocking probability in adaptive multimedia wireless Networks, "in Proceedings of the 25th IEEE International Performance, Computing, and communications Conference (IPCCC '06), vol. 2006, pp. 647-652, New Orleans, LA, USA.

[12] Boggia, P. C., and Di Fonzo, N., 2003. Teletraffic analysis of hierarchical cellular comunication networks, "IEEE Transactions on Vehicular Technology, vol. 52, no. 4, pp. 931-946.

[13] www.directionsmag.com/gsm-network-qualitymonitoring-a- Nigerian-case-study/123278

[14] www.ncc.gov.ng/directorate of technical research \& standards 